\title{
Interleukin 11 regulates endometrial cancer cell adhesion and migration via STAT3
}

\author{
VIRGINIA LAY $^{1,2^{*}}$, JOANNE YAP $^{1^{*}}$, STEFAN SONDEREGGER $^{1}$ and EVDOKIA DIMITRIADIS ${ }^{1,2}$ \\ ${ }^{1}$ Prince Henry's Institute of Medical Research; ${ }^{2}$ Department of Anatomy and Developmental Biology, \\ Monash University, Clayton, VIC 3168, Australia
}

Received February 17, 2012; Accepted April 12, 2012

DOI: 10.3892/ijo.2012.1486

\begin{abstract}
Endometrial carcinoma is the most common gynaecological malignancy. There is however a lack of curative therapies, especially for patients diagnosed with late stage, recurrent or aggressive disease, who have a poor prognosis. Interleukin (IL) 11 is a pleiotropic cytokine that has a role in a number of cancers including colon and breast cancer. IL11 was recently found to be upregulated in endometrial cancers, however the function of IL11 in endometrial cancer is not known. This study aimed to determine the effects of IL11 on endometrial cancer cell proliferation, adhesion and migration. Three endometrial cancer cell lines, Ishikawa, HEC-1A and AN3CA (derived from endometrial cancers grade I, II and III, respectively), were used to determine the effect of IL11 on endometrial cancer cell function. Cell proliferation and viability were assessed by BrdU and Wst-1 assays. Cell adhesion to the extracellular matrix proteins fibronectin, collagen I and IV, vitronectin and laminin was assessed. Modified boyden chambers were utilized to access IL11 action on migration and invasion, respectively. The specific effect of IL11 action on these processes was determined using a unique IL11 inhibitor. IL11 phosphorylated (p)-STAT3 protein abundance in all 3 cell lines but had no effect on pERK and pAKT abundance. Similarly, IL11 had no effect on cell proliferation and viability but increased adhesion of ANC3A cells to fibronectin while having no effect on the other extracellular matrix proteins. IL11 did not alter the adhesive properties of the Ishikawa and HEC-1A cells. In the AN3CA cells, IL11 treatment resulted in a $50 \%$ increase in migration and co-treatment with the specific IL11 inhibitor or a STAT3 inhibitor abolished the effect. This study shows a role for IL11 in endometrial cancer and suggests IL11 may be involved in endometrial cancer development and thus may be useful as a therapeutic target.
\end{abstract}

Correspondence to: Dr Evdokia Dimitriadis, Prince Henry's Institute of Medical Research, Clayton, VIC 3168, Australia

E-mail: evdokia.dimitriadis@princehenrys.org

*Contributed equally

Key words: cytokines, endometrial cancer, signal transducer and activator of transcription, migration

\section{Introduction}

Endometrial carcinoma (EC) is the most common gynaecological malignancy in the Western world (1). The rate is rising in developed countries, most likely due to the rise in obesity and increased life expectancies (2).

EC can be classified into two groups (3): type I lesions develop from excess unopposed estrogen stimulation of the endometrium, causing hyperplasia, which may progress to malignancy. These cancers typically occur in younger, pre-menopausal women, are diagnosed earlier and have a good prognosis. Type II tumours are estrogen independent. They commonly occur in older, post-menopausal women, are diagnosed much later than type I tumours and are usually more aggressive histological subtypes (clear cell or serous carcinoma). These high grade tumours have frequently already undergone extensive invasion of surrounding structures or lymph node or distant metastases, hence have a very poor prognosis.

Unfortunately, there is currently no appropriate screening test available for EC. The main treatment strategy is surgical, involving a total abdominal hysterectomy and bilateral salpingo-oophorectomy. There is a lack of curative therapies for patients diagnosed with late stage, recurrent or aggressive disease. Adjuvant chemotherapy or radiotherapy is used for patients with advanced disease (4). Hormonal treatment with progestins are used clinically, but response is restricted to those with hormone receptor-positive tumours, and recurrence rate is high (5). Therefore, the identification of novel factors involved in cancer progression is important in the development of new pharmacological therapies to improve $\mathrm{EC}$ prognosis.

Interleukin (IL) 11 is a member of the IL6 family of cytokines. It signals via the IL11 receptor (R) $\alpha$ and gp130 receptor complex to activate the Janus tyrosine kinases (JAK). This, in turn, can induce the activation of three independent downstream signalling pathways: the signal transducer and activator of transcription (STAT) pathway, the Ras-mitogen activated protein kinase (MAPK) pathway; and the phosphotidylinositol-3 kinase (PI-3K) pathway (6). In the human endometrium, IL11 primarily acts via STAT3 (7). IL11 is a critical factor in the establishment of pregnancy and is associated with several pathologies of pregnancy (8-10). Moreover, current studies have found a role for IL11 in trophoblast migration and invasion $(11,12)$, processes that are similar to that of cancer progression. While both trophoblast invasion and cancer cell invasion are similar, 
trophoblast invasion is a highly controlled process unlike that of cancer cell invasion.

Studies have reported a role for IL11 in several epithelial cancers, including breast (13), gastric (14) and colorectal cancer (15). ECs show elevated levels of IL11 and IL11R $\alpha$ mRNA compared to normal proliferative phase endometrium (16). Furthermore, we have demonstrated that IL11 protein is upregulated in EC tissue and uterine lavage fluid, compared to control post-menopausal endometrial tissue and lavage fluid respectively (17). Whilst this evidence shows that IL11 is produced by EC, its function in EC is not yet known. In this study, we investigated the effects of IL11 on proliferation, adhesion and migration in endometrial cancer cell lines. We also investigated the effects of IL11 inhibition on these actions.

\section{Materials and methods}

Materials. Human recombinant IL11 was obtained from R\&D Systems (Sydney, Australia) and diluted in $0.1 \%$ bovine serum albumin (BSA) in phosphate-buffered saline (PBS). STAT3 phosphorylation inhibitor (STAT3i; $20 \mu \mathrm{M}$; Calbiochem, San Diego, CA, USA). PEGylated IL11 inhibitor (IL11 inhibitor) was produced by CSL Limited (Melbourne, Australia) $(18,19)$.

Cell lines. Three endometrial cancer cell lines were used: Ishikawa, HEC-1A and AN3CA cells, which are derived from grade I, II and III EC, respectively (20-22). The cell lines were cultured in DMEM, McCoy's or MEM (Invitrogen, Melbourne, Australia) respectively and supplemented with $10 \%$ fetal bovine serum (FBS; SAFC Biosciences, Lenexa, KS, USA), $1 \%$ L-glutamine (Invitrogen) and $1 \%$ penicillin-streptomycin (Invitrogen).

SDS-PAGE and western blot analysis. Confluent cells were serum starved for $24 \mathrm{~h}$ before treatment with control, IL11 (100 ng/ml, concentration chosen from previous studies and concentration-response studies) (11) for 10, 30 or $60 \mathrm{~min}$. Cell lysates were collected using lysis buffer [50 mM Tris-Base, $150 \mathrm{mM} \mathrm{NaCl}, 2 \mathrm{mM}$ EDTA, $2 \mathrm{mM}$ EGTA, $25 \mathrm{mM} \mathrm{NaF}$, and $25 \mathrm{mM}$ B glycerolphosphate ( $\mathrm{pH}$ 7.5)] containing protease inhibitor ( $2 \mu \mathrm{l} / \mathrm{ml}$; ThermoScientific, Waltham, MA, USA). Cell lysate $(20 \mu \mathrm{g})$ was loaded and electrophoresed on a 10\% SDS-PAGE gel. The protein was transferred to polyvinylidene fluoride (PVDF) membranes before it was incubated with phosphorylated (p)-STAT3 (Tyr705) (no. 9131), total STAT3 (no. 9132), phosphorylated (p)-p44/42 MAPK (Erk1/2) (Thr202/Tyr204) (no. 4370), total p44/42 MAPK (Erk1/2) (no. 4695) phosphorylated (p)-AKT (Ser473) (no. 4058) and total AKT (pan) (no. 4691) (Cell Signaling Technology, Danvers, MA, USA) primary antibodies overnight at $4^{\circ} \mathrm{C}$. Membranes were incubated with horseradish peroxidase (HRP)-conjugated secondary antibody (50 $\mu \mathrm{g} / \mathrm{l}$; DakoCytomation) and HRP activity visualized using the enhanced chemiluminescence system (ThermoScientific). Membranes were exposed to film and developed, and the relative band intensity determined using densitometric analysis (ImageJ v1.43, National Institutes of Health, Bethesda, MD, USA).

Enzyme-linked immunoassays (ELISAs). Phosphorylated (p)-STAT3 and total STAT3 were measured using an established sandwich-ELISA (Cell Signaling Technology) according to manufacturer's protocol. Prior to assay, confluent cells were serum starved for $24 \mathrm{~h}$ before treatment with control, IL11 $(100 \mathrm{ng} / \mathrm{ml})$ + PEGylated IL11 inhibitor (IL11 inhibitor; $10 \mu \mathrm{g} / \mathrm{ml}$ ) or IL11 inhibitor alone $(10 \mathrm{~g} / \mathrm{ml})$. Cell lysates were collected using lysis buffer [50 mM Tris-Base, $150 \mathrm{mM} \mathrm{NaCl}, 2 \mathrm{mM}$ EDTA, $2 \mathrm{mM}$ EGTA, $25 \mathrm{mM} \mathrm{NaF}$, and $25 \mathrm{mM}$ B glycerolphosphate (pH 7.5)] containing protease inhibitors $(2 \mu \mathrm{l} / \mathrm{ml}$; ThermoScientific).

Briefly, a 96-well plate was incubated overnight at $4^{\circ} \mathrm{C}$ with capture antibody. The plate was washed and blocked with blocking buffer (1X PBS, 0.05\% Tween-20, 1\% BSA) for $1 \mathrm{~h}$ at $37^{\circ} \mathrm{C}$. The plate was washed four times and then incubated with $30 \mu \mathrm{g}$ of protein lysates per well for $2 \mathrm{~h}$ at $37^{\circ} \mathrm{C}$. A further wash was required followed by incubation with detection antibody for $1 \mathrm{~h}$ at $37^{\circ} \mathrm{C}$. Following this, the plate was washed and secondary antibody was applied for $30 \mathrm{~min}$ at $37^{\circ} \mathrm{C}$ before measuring the absorbance at $450 \mathrm{~nm}$ with a Wallac Envision 2103 plate reader (Perkin Elmer).

Bromodeoxyuridine (BrdU) assay. BrdU ELISA kit (Roche Applied Science, Indianapolis, IN, USA) was used to assess cell proliferation as per the manufacturer's instructions and as previously described (12). Briefly, cells were seeded into 96-well plates (5,000 cells/well) and allowed to adhere for $8 \mathrm{~h}$. They were then serum starved for $24 \mathrm{~h}$ before treatment with control, IL11 [100 ng/ml + IL11 inhibitor $(10 \mu \mathrm{g} / \mathrm{ml})]$ for $48 \mathrm{~h}$ at $37^{\circ} \mathrm{C}$. $\operatorname{BrdU}(10 \mathrm{mM})$ was added to each well and incubated for $2 \mathrm{~h}$ at $37^{\circ} \mathrm{C}$. BrdU incorporation was measured at $450 \mathrm{~nm}$ with a Wallac Envision 2103 plate reader (Perkin Elmer).

WST-1 assay. A Wst-1 assay was used to determine the effect of IL11 on cell viability as previously described (12). Cells were seeded into 96-well plates (10,000 cells/well) and allowed to adhere for $8 \mathrm{~h}$. Cells were then serum starved for $24 \mathrm{~h}$ before treatment with control, IL11 [100 + IL11 inhibitor $(10 \mu \mathrm{g} / \mathrm{ml}) \mathrm{ng} / \mathrm{ml}$ ] for $48 \mathrm{~h}$ at $37^{\circ} \mathrm{C}$. Wst-1 dye $(1: 10$; Roche Applied Science) was then added to each well and incubated for $4 \mathrm{~h}$ at $37^{\circ} \mathrm{C}$. The viable cell number was determined by measuring the absorbance at $450 \mathrm{~nm}$ with a Wallac Envision 2103 plate reader (Perkin Elmer).

Adhesion assay. To determine the effect of IL11 on cell adhesion, CytoMatrix cell adhesion strips (Millipore, Sydney, Australia) coated with extracellular matrix (ECM) proteins (fibronectin, laminin, collagen I, collagen IV and vitronectin) were used according to the manufacturer's instructions. Briefly, cells were serum starved for $24 \mathrm{~h}$, then treated with IL11 [100 or $100+$ IL11 inhibitor $(10 \mu \mathrm{g} / \mathrm{ml})]$. Cells were seeded [50,000 (Ishikawa and HEC-1A) or 60,000 (AN3CA)] into the wells and incubated for $2 \mathrm{~h}$ at $37^{\circ} \mathrm{C}$. Non-adherent cells were washed off and adherent cells stained with $0.2 \%$ crystal violet in $50 \%$ ethanol solution. The stain was eluted with solubilisation buffer (1:1 solution of $\mathrm{NaH}_{2} \mathrm{PO}_{4}$ and $50 \%$ ethanol) and absorbance was read at $560 \mathrm{~nm}$ with a Wallac Envision 2103 plate reader (Perkin Elmer).

Migration assay. Chemotaxis cell (96-well) migration kits (Millipore) were used according to the manufacturer's instructions to assess chemotactic cell migration. Briefly, 50,000 cells in $1 \%$ FBS were seeded into each of the upper wells. Cells were pre-treated with the STAT-3 inhibitor $(10 \mu \mathrm{M})$ for $18 \mathrm{~h}$ prior to the migration assay $(11,23)$. Control, IL11 [(100 ng/ml) or IL11 
$(100 \mathrm{ng} / \mathrm{ml})+\mathrm{IL} 11$ inhibitor $(10 \mu \mathrm{g} / \mathrm{ml})]$ was added to the lower wells and cells were incubated for $24 \mathrm{~h}$ at $37^{\circ} \mathrm{C}$. A positive control consisting of $10 \%$ FCS was added to the lower chamber as previously described (12). Migrated cells were detached, lysed and quantified with a dye by measuring the fluorescence at 485/535 with a Wallac Envision 2103 plate reader (Perkin Elmer).

Statistical analysis. All data are expressed as mean \pm standard error of the mean (SEM) fold change in comparison to control for graphical representation. Raw data were analysed using GraphPad Prism 5 (GraphPad Software, San Diego, CA, USA) for Windows. The raw data were tested for normal distribution and the appropriate statistical test utilized as described below. All functional assays had a minimum of 3 independent experiments in triplicate wells, unless otherwise stated. Normally distributed data were analysed statistically by one-way analysis of variance for three or more groups or a paired t-test was used to analyse differences between two groups. Not normally distributed data were analysed by Mann-Whitney (comparison of two groups) or Kruskal-Wallis (comparison of three of more groups) tests. A p-value of $<0.05$ was considered statistically significantly different between groups.

\section{Results}

IL11 signals via STAT3 in endometrial cancer cell lines. We examined the effect of IL11 on three downstream intracellular pathways. IL11 (100 ng/ml) phosphorylated (p)-STAT3 in all three cell lines after $10 \mathrm{~min}$ (Fig. 1A) and had no effect on STAT3 protein abundance. Moreover, a sandwich-ELISA, used for quantitative STAT3 phosphorylation analysis in the AN3CA cells, demonstrated that IL11 $(100 \mathrm{ng} / \mathrm{ml})$ significantly upregulated (p)-STAT3 compared to control and this was reversed by co-treatment with the IL11 inhibitor (Fig. 1B). Treatment of ANC3A cells with IL11 inhibitor alone or IL11 at a concentration of $1 \mathrm{ng} / \mathrm{ml}$ did not alter (p)-STAT3 compared to control. As IL11 is known to activate a number of other signalling pathways in cancer cells we investigated whether IL11 altered the MAPK or PI3K pathways. We demonstrated that IL11 did not activate/ enhance the MAPK or PI3K signalling pathways in Ishikawa, HEC-IA and ANC3A cells [Fig. 1C (i) and (ii)].

IL11 had no effect on cell proliferation or viability. To determine the effect of IL11 on cell proliferation and cell viability, BrdU and Wst-1 assays were used, respectively. IL11 (100 ng/ $\mathrm{ml})$ or IL11 $(100 \mathrm{ng} / \mathrm{ml})+\mathrm{IL} 11$ inhibitor $(10 \mu \mathrm{g} / \mathrm{ml})$ had no significant effect on cell proliferation (BrdU; Fig. 2A) or cell viability (Wst-1; Fig. 2B) in the three cell lines. IL11 inhibitor alone did not affect cell proliferation (data not shown).

IL11 alters endometrial cancer cell adhesion. Using the three different cell lines Ishikawa, HEC-1A and AN3CA (as models of grade I, II and III, respectively) we investigated the effects of IL11 on EC cell adhesion to ECM proteins. AN3CA cells showed maximal binding to fibronectin, laminin and vitronectin but no binding to both collagen I and IV (Fig. 3A). AN3CA cells treated with IL11 (100 ng/ml) increased binding to fibronectin $(\mathrm{P}<0.05)$; Fig. 3B) compared to control. Co-culture of AN3CA cells with IL11 (100 ng/ml) and IL11 inhibitor or STAT3 inhibitor significantly decreased adhesion to fibronectin compared
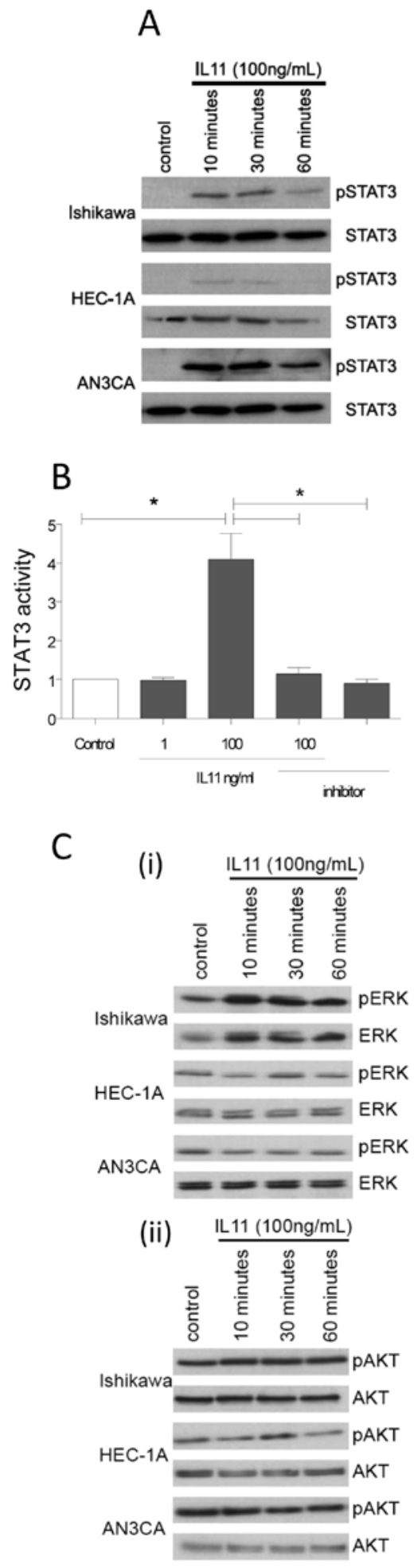

Figure 1. IL11 signals via phosphorylated STAT3 in AN3CA, Ishikawa and HEC-1A cells. (A) Cells were cultured with IL11 (100 ng/ml) and the abundance of phosphorylated (p) STAT3 and STAT3 was determined after 10, 30 and $60 \mathrm{~min}$. Data are representative of $n=3$ experiments. (B) pSTAT3 ELISA assay: ANC3A cells were treated with control, IL11 [1, 100, $100 \mathrm{ng} /$ $\mathrm{ml}+$ PEGylated IL11 inhibitor (IL11 inhibitor; $10 \mu \mathrm{g} / \mathrm{ml}$ ) and IL11 inhibitor $(10 \mu \mathrm{g} / \mathrm{ml})$ alone] for $10 \mathrm{~min}$. Data are expressed as mean (expressed as fold change from control) \pm SEM and represents triplicate treatments from $n=3$ individual experiments. ${ }^{*} \mathrm{P}<0.05$; IL11 $(100 \mathrm{ng} / \mathrm{ml})$ compared to all other groups. (C) Effect of IL11 on ERK and AKT phosphorylation in Ishikawa, HEC-1A and AN3CA cells. Cells were cultured with control, IL11 (100 ng/ml) for 10,30 and $60 \mathrm{~min}$. Following western blot analysis protein bands for pERK (42, $44 \mathrm{kDa})$, total ERK (42, $44 \mathrm{kDa}), \mathrm{p}-S e r 473-\mathrm{AKT}$ (60 kDa) and total AKT $(60 \mathrm{kDa})$ were detected. Data are representative of two independent experiments assayed in triplicate. 

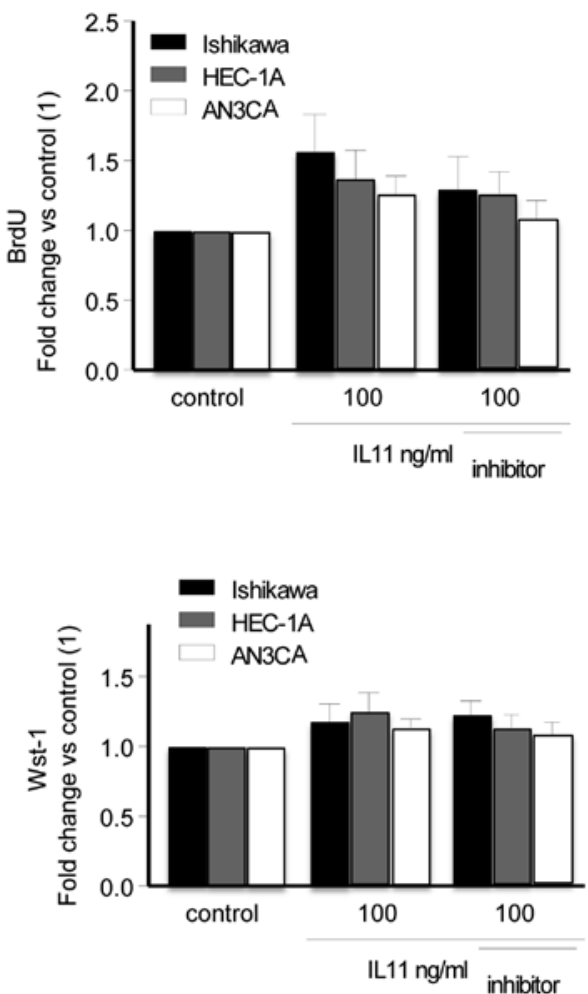

Figure 2. IL11 does not alter viability or proliferation of AN3CA, Ishikawa and HEC-1A cells. Cell proliferation and cell viability were assessed by BrdU and by Wst- 1 assays respectively as detailed in Materials and methods. Cells were treated with control, IL11 (100 ng/ml IL11) and IL11 (100 ng/ml) + IL11 inhibitor $(10 \mu \mathrm{g} / \mathrm{ml})$ and cell proliferation and viability assessed. Data are expressed as mean (expressed as fold change from control) \pm SEM and represents triplicate treatments from $n=5$ independent experiments.

to cells treated with IL11 (100 ng/ml) (Fig. 3B). Treatment of Ishikawa and HEC-1A cells with IL11 (100 ng/ml) did not significantly alter cell adhesion to the ECM (data not shown).

IL11 regulates ANC3A cell migration via STAT3. The effect of IL11 on cell migration was examined in ANC3A, Ishikawa and HEC-1A cells (Fig. 4). AN3CA cells treated with IL11 $(100 \mathrm{ng} / \mathrm{ml})$ resulted in a $50 \%$ increase in cell migration compared to control ( $\mathrm{P}<0.05$; Fig. 4). This effect was reversed by co-incubation with IL11 $(100 \mathrm{ng} / \mathrm{ml})$ and the IL11 specific inhibitor $(10 \mu \mathrm{g} / \mathrm{ml})$ (Fig. 4). Similarly, ANC3A cells co-incubated with IL11 and the STAT3 inhibitor reduced cell migration compared to cells treated with IL11 alone. By contrast, IL11 had no effect on Ishikawa and HEC-1A cell migration (Fig. 4).

\section{Discussion}

This study investigated the effect of IL11 in endometrial cancer cell function - proliferation, viability, adhesion and migration using three human endometrial carcinoma cell lines (Ishikawa, HEC-1A and AN3CA). We demonstrated that IL11 increased cell adhesion of ANC3A cells to fibronectin but did not affect Ishikawa and HEC-1A cell adhesive properties. IL11 had no effect on cell proliferation or viability. By contrast, IL11 increased AN3CA cell migration while it did not significantly alter Ishikawa or HEC-1A cell migration. A unique IL11 inhibitor reversed the observed effects on both cell adhesion
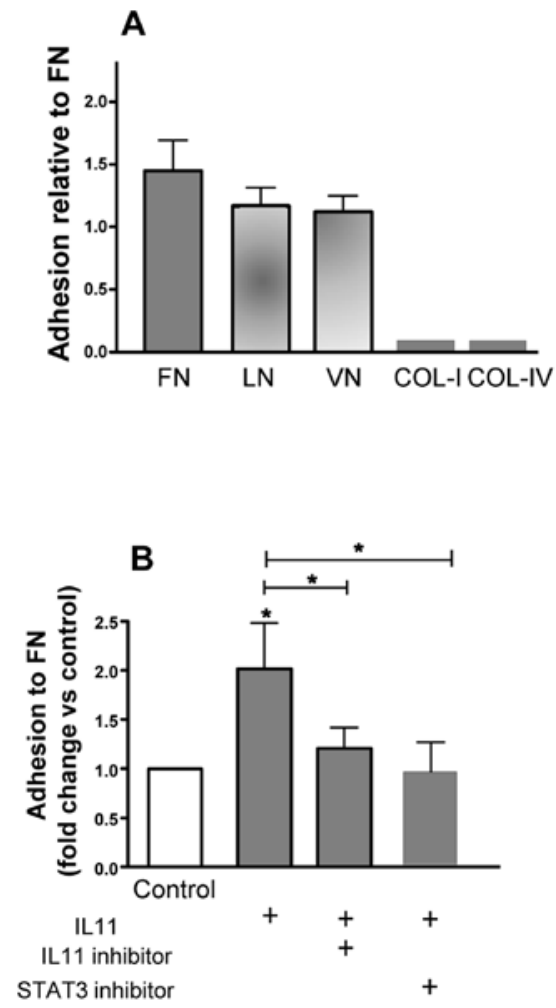

Figure 3. Effect of IL11 on ANC3A cell adhesion to extracellular matrix proteins. (A) Cell adhesion to collagen I (COL-1), collagen IV (COL-IV), fibronectin (FN) and vitronectin (VN) and laminin (LN) was determined using Cytomatrix Cell adhesion assays as detailed in the Materials and methods. (B) Cells were pre-treated with combinations of control, IL11 (100 ng/ml), IL11 inhibitor $(10 \mu \mathrm{g} / \mathrm{ml})$, STAT3 inhibitor $(20 \mu \mathrm{M})$ for $24 \mathrm{~h}$ prior to the adhesion assays. Cells were then transfered to FN coated plates for 90 min for measurement of cell adhesion to FN. Data are expressed as mean \pm SEM and represents triplicate treatments from $n=5$ (inhibitor studies; $n=3$ ) individual experiments. ${ }^{*} \mathrm{P}<0.05$ compared to control or between groups as indicated.

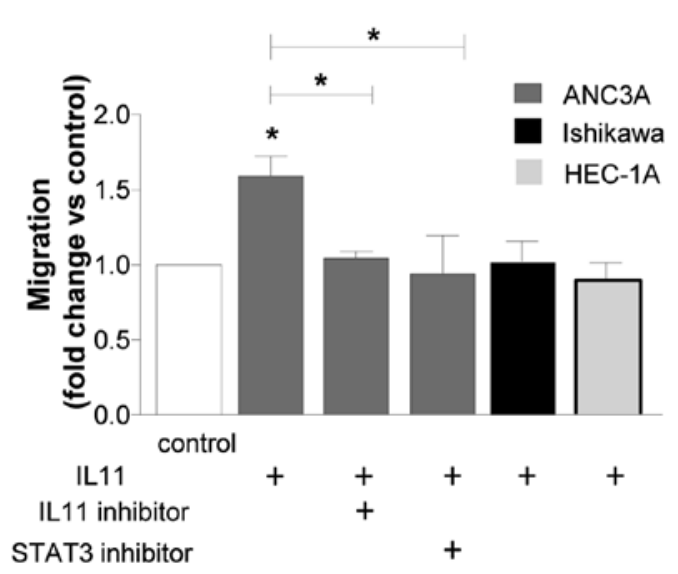

Figure 4. Effect of IL11 on AN3CA, Ishikawa and HEC-1A cell migration. Cells were treated with control, IL11 $(100 \mathrm{ng} / \mathrm{ml})$ and IL11 $(100 \mathrm{ng} / \mathrm{ml})+$ IL11 inhibitor $(10 \mu \mathrm{g} / \mathrm{ml})$ for $24 \mathrm{~h}$ and then assessed. Data are expressed as mean (expressed as fold change from control) \pm SEM and represents triplicate treatments from $n=3$ individual experiments. ${ }^{*} \mathrm{P}<0.05$ compared to control or between groups as shown.

and migration. Similarly, a STAT3 inhibitor blocked the IL11 mediated effects on ANC3A cell adhesion suggesting IL11 regulated these processes via (p)-STAT3. In agreement, IL11 
phosphorylated (p)-STAT3 and did not affect the MAPK or PI3K pathways in the Ishikawa, HEC-1A and AN3CA cells.

IL11 signalling is initiated via the IL11R $\alpha$ and the gp130 receptor complex (24). In the endometrium, IL11 primarily signals via the JAK/STAT intracellular pathway (25). This is also the case in endometrial cancer cells as demonstrated in the present study. JAK/STAT signalling has been well studied in other cancers (26), including breast cancer, pancreatic, colorectal, prostate and head and neck cancer as well as leukaemia and lymphoma (27). Evidence shows that inappropriate STAT activation results in an environment that is conducive to tumour development, such as inhibition of apoptosis, promotion of angiogenesis and proliferation (28). For instance, IL11 signals via STAT3 to increase tumourigenesis in gastric cancer, as demonstrated with a gp130 Y757 knock-in mutant mouse model (14). In the present study we demonstrated that blocking the IL11 pathway inhibited adhesion and migration of the ANC3A cells that were derived from grade III (undifferentiated) tumours via the activation of STAT3.

IL11 had no effect on cell proliferation or viability in all three cancer cell lines tested. This finding is consistent with the lack of effect of IL11 on proliferation of human trophoblast cells (12), lung and colon cancers (29). It is well known that IL11 has an anti-apoptotic effect under stressful conditions. In the gastrointestinal system, IL11 protects against mucosal injury in diseases such as inflammatory bowel disease, intestinal ischemia, necrotising enterocolitis and irradiation. However, from our data, it is unlikely that IL11 prevents apoptosis due to the lack of effect on cell proliferation and cell viability.

We demonstrated that IL11 significantly altered ANC3A cell adhesion to fibronectin, while no significant effect was seen with the other extracellular matrix proteins tested and furthermore no effect on Ishikawa and HEC-1A cell adhesion was detected. By comparison we previously demonstrated that IL11 stimulated cell adhesion of human endometrial epithelial cells to fibronectin and collagen IV, as well as primary trophoblast cells (30). Integrins are likely candidates by which cells regulate adhesion (22). Whether IL11 regulates integrins in endometrial cancer cells, however, remains to be determined. Tumours of higher grades are more likely to be less adhesive, lending themselves to a more migratory phenotype. This has been found in pancreatic (31) and prostate cancer (32). Paradoxically, the present study demonstrated IL11 increased ANC3A cell adhesion to fibronectin and migration. Cell migration involves the adhesion and de-adhesion of cells and our data suggest there may be mechanisms additional to cell adhesion by which IL11 facilitated ANC3A cell migration. A recent study reported, that fibronectin gene expression is reduced in endometrial cancer tissue compared to normal endometrium and suggest that fibronectin may be useful as a marker of disease progression (33).

IL11 increased migration of ANC3A cells via (p)-STAT3 while no effect was seen with IL11 on Ishikawa and HEC-1A cell migration. IL11 maximally activated (p)-STAT3 in the ANC3A cells compared to the Ishikawa and HEC-1A cells suggesting that IL11 was less responsive to the latter two cell lines. Interestingly, Ishikawa and HEC-1A cells are derived from grade I and II endometrial cancers, while ANC3A cell are derived from grade III cancers suggesting that IL11 has a role primarily in the migratory higher grade tumours. Similarly, IL11 has previously been demonstrated to stimulate the migration of
EVT-hybridoma cells (12) and outgrowth of primary extravillous trophoblast cells (23). In other cancers such as colorectal cancer, IL11 increases cell migration via the PI3K pathway and inhibiting this pathway reverses the effect (15). Similarly IL11 stimulates migration in other cells, including breast cancer cell lines (34) and endothelial progenitor cells (35).

A number of studies demonstrate that IL11 increases the invasive capacity of many other cancers. IL11 increases invasion of JEG3 choriocarcinoma cells (36), squamous cell carcinomas (29) and breast cancer cells (37). In gastric cancer, IL11 promotes cellular invasion via the STAT3 pathway (14). Similarly, in colorectal cancer, IL11 levels are associated with the extent of tumour invasion and infiltration into vessels (15).

In conclusion, these results demonstrate a role for IL11 in endometrial carcinoma cells likely acting via (p)-STAT3. IL11 is upregulated in grade I tumours and in uterine lavage fluid (17) suggesting IL11 may be useful as a marker for endometrial cancer. This study supports a role for IL11 in endometrial cancer progression and in vivo studies are required to determine whether targeting IL11 may be useful as a treatment option for endometrial cancer progression.

\section{Acknowledgements}

We thank Dr Ellen Menkhorst for her contribution in editing the manuscript and technical advice. We thank Kirsten Edwards, Brent McKenzie, Andrew Nash and Pierre Scotney from CSL Biotherapies for provision of the IL11 antagonist. This study was funded by the NHMRC of Australia: ED is the funding recipient of Career Development Fellowship no. 550905 and V.L., J.Y. and S.S. are funded from project grant no. 388901. The study was also supported by the Victorian Government's Operational Infrastructure Support Program. PHI Data Audit 11-16.

\section{References}

1. Australian Institute of Health and Welfare (AIHW); Australasian Association of Cancer Registries (AACR): Cancer in Australia: an overview, 2008. Cancer series no. 46. Cat. no. CAN 42. AIHW, Canberra, 2008.

2. Amant F, Moerman P, Neven P, Timmerman D, Van Limbergen E and Vergote I: Endometrial cancer. Lancet 366: 491-505, 2005.

3. Bokhman JV: Two pathogenetic types of endometrial carcinoma. Gynecol Oncol 15: 10-17, 1983.

4. Tangjitgamol S, Anderson BO, See HT, et al: Management of endometrial cancer in Asia: consensus statement from the Asian Oncology Summit 2009. Lancet Oncol 10: 1119-1127, 2009.

5. Niwa K, Tagami K, Lian Z, Onogi K, Mori H and Tamaya T: Outcome of fertility-preserving treatment in young women with endometrial carcinomas. BJOG 112: 317-320, 2005.

6. Heinrich PC, Behrmann I, Haan S, Hermanns HM, MullerNewen G and Schaper F: Principles of interleukin (IL)-6-type cytokine signalling and its regulation. Biochem J 374: 1-20, 2003.

7. Dimitriadis E, Stoikos C, Tan YL and Salamonsen LA: Interleukin 11 signaling components signal transducer and activator of transcription 3 (STAT3) and suppressor of cytokine signaling 3 (SOCS3) regulate human endometrial stromal cell differentiation. Endocrinology 147: 3809-3817, 2006.

8. Chen HF, Lin CY, Chao KH, Wu MY, Yang YS and Ho HN: Defective production of interleukin-11 by decidua and chorionic villi in human anembryonic pregnancy. J Clin Endocrinol Metab 87: 2320-2328, 2002.

9. Karpovich N, Chobotova K, Carver J, Heath JK, Barlow DH and Mardon HJ: Expression and function of interleukin-11 and its receptor alpha in the human endometrium. Mol Hum Reprod 9: 75-80, 2003. 
10. von Rango U, Alfer J, Kertschanska S, et al: Interleukin-11 expression: its significance in eutopic and ectopic human implantation. Mol Hum Reprod 10: 783-792, 2004.

11. Paiva P, Salamonsen LA, Manuelpillai U and Dimitriadis E: Interleukin 11 inhibits human trophoblast invasion indicating a likely role in the decidual restraint of trophoblast invasion during placentation. Biol Reprod 80: 302-310, 2009.

12. Paiva P, Salamonsen LA, Manuelpillai U, et al: Interleukin-11 promotes migration, but not proliferation, of human trophoblas cells, implying a role in placentation. Endocrinology 148: 5566-5572, 2007.

13. Hanavadi S, Martin TA, Watkins G, Mansel RE and Jiang WG: Expression of interleukin 11 and its receptor and their prognostic value in human breast cancer. Ann Surg Oncol 13: 802-808, 2006.

14. Ernst M, Najdovska M, Grail D, et al: STAT3 and STAT1 mediate IL-11-dependent and inflammation-associated gastric tumorigenesis in gp130 receptor mutant mice. J Clin Invest 118 : 1727-1738, 2008.

15. Yamazumi K, Nakayama T, Kusaba T, et al: Expression of interleukin-11 and interleukin-11 receptor alpha in human colorectal adenocarcinoma; immunohistochemical analyses and correlation with clinicopathological factors. World J Gastroenterol 12 : 317-321, 2006

16. Sales KJ, Grant V, Cook IH, et al: Interleukin-11 in endometrial adenocarcinoma is regulated by prostaglandin F2alpha-F-prostanoid receptor interaction via the calciumcalcineurin-nuclear factor of activated $\mathrm{T}$ cells pathway and negatively regulated by the regulator of calcineurin- 1 . Am J Pathol 176: 435-445, 2010.

17. Yap J, Salamonsen LA, Jobling T, Nicholls PK and Dimitriadis E: Interleukin 11 is upregulated in uterine lavage and endometrial cancer cells in women with endometrial carcinoma. Reprod Biol Endocrinol 8: 63, 2010

18. Lee CG,Hartl D, Matsuura H, et al: Endogenous IL-11 signaling is essential in Th2- and IL-13-induced inflammation and mucus production. Am J Resp Cell Mol Biol 39: 739-746, 2008.

19. Menkhorst E, Salamonsen L, Robb L and Dimitriadis E: IL11 antagonist inhibits uterine stromal differentiation, causing pregnancy failure in mice. Biol Reprod 80: 920-927, 2009.

20. Dimitriadis E, Stoikos C, Baca M, Fairlie WD, McCoubrie JE and Salamonsen LA: Relaxin and prostaglandin E(2) regulate interleukin 11 during human endometrial stromal cell decidualization. J Clin Endocrinol Metab 90: 3458-3465, 2005.

21. Hilton DJ, Hilton AA, Raicevic A, et al: Cloning of a murine IL-11 receptor alpha-chain; requirement for gp130 for high affinity binding and signal transduction. EMBO J 13: 4765-4775, 1994.

22. Marwood M, Visser K, Salamonsen LA and Dimitriadis E: Interleukin-11 and leukemia inhibitory factor regulate the adhesion of endometrial epithelial cells: implications in fertility regulation. Endocrinology 150: 2915-2923, 2009.
23. Sonderegger S, Yap J, Menkhorst E, Weston G, Stanton PG and Dimitriadis E: Interleukin (IL) 11 mediates protein secretion and modification in human extravillous trophoblasts. Hum Reprod 26: 2841-2849, 2011.

24. Painter KJ, Armstrong NJ and Sherratt JA: The impact of adhesion on cellular invasion processes in cancer and development. J Theor Biol 264: 1057-1067, 2010.

25. Arao S, Masumoto A and Otsuki M: Beta1 integrins play an essential role in adhesion and invasion of pancreatic carcinoma cells. Pancreas 20: 129-137, 2000.

26. Torimura T, Ueno T, Kin M, et al: Integrin alpha6betal plays a significant role in the attachment of hepatoma cells to laminin. J Hepatol 31: 734-740, 1999

27. Nakahara H, Nomizu M, Akiyama SK, Yamada Y, Yeh Y and Chen WT: A mechanism for regulation of melanoma invasion. Ligation of alpha6beta1 integrin by laminin $\mathrm{G}$ peptides. J Biol Chem 271: 27221-27224, 1996.

28. Lessey BA: Integrins and the endometrium: new markers of uterine receptivity. Ann NY Acad Sci 828: 111-122, 1997.

29. Wang J, Homer RJ, Hong L, et al: IL-11 selectively inhibits aeroallergen-induced pulmonary eosinophilia and $\mathrm{Th} 2$ cytokine production. J Immunol 165: 2222-2231, 2000.

30. Luo X, Ding L and Chegini N: Gonadotropin-releasing hormone and TGF-beta activate MAP kinase and differentially regulate fibronectin expression in endometrial epithelial and stromal cells. Am J Physiol Endocrinol Metab 287: E991-E1001, 2004

31. Jarnicki A, Putoczki T and Ernst M: Stat3: linking inflammation to epithelial cancer - more than a 'gut' feeling? Cell Div 5: 14 , 2010.

32. Seval Y, Cakmak H, Kayisli UA and Arici A: Estrogen-mediated regulation of p38 mitogen-activated protein kinase in human endometrium. J Clin Endocrinol Metab 91: 2349-2357, 2006.

33. Futyma K, Kubiatowski T, Rozynska K, et al: Decreased osteonectin and fibronectin gene expression in endometrial cancer cancer as a prognostic marker. Ginekol Pol 80: 907-913, 2009 (In Polish).

34. Soda H, Raymond E, Sharma S, et al: Recombinant human interleukin-11 is unlikely to stimulate the growth of the most common solid tumors. Anticancer Drugs 10: 97-101, 1999.

35. Pignatelli M, Ansari TW, Gunter P, et al: Loss of membranous E-cadherin expression in pancreatic cancer: correlation with lymph node metastasis, high grade, and advanced stage. J Pathol 174: 243-248, 1994.

36. Suman P, Poehlmann TG, Prakash GJ, Markert UR and Gupta SK: Interleukin-11 increases invasiveness of JEG-3 choriocarcinoma cells by modulating STAT3 expression. J Reprod Immunol 82: 1-11, 2009.

37. Gentilini D, Busacca M, Di Francesco S, Vignali M, Vigano P and Di Blasio AM: PI3K/Akt and ERK1/2 signalling pathways are involved in endometrial cell migration induced by 17 betaestradiol and growth factors. Mol Hum Reprod 13: 317-322, 2007. 